\title{
L'Image du Sápmi, Études comparées, textes réunis par Kajsa Andersson
}

\section{Michel Arrous}

\section{(2) OpenEdition}

1 Journals

Édition électronique

URL : http://journals.openedition.org/studifrancesi/5985

DOI : 10.4000/studifrancesi.5985

ISSN : 2427-5856

Éditeur

Rosenberg \& Sellier

\section{Édition imprimée}

Date de publication : 1 mai 2011

Pagination : 179-180

ISSN : 0039-2944

\section{Référence électronique}

Michel Arrous, "L'Image du Sápmi, Études comparées, textes réunis par Kajsa Andersson », Studi

Francesi [En ligne], 163 (LV | I) | 2011, mis en ligne le 30 novembre 2015, consulté le 13 janvier 2021

URL : http://journals.openedition.org/studifrancesi/5985; DOI : https://doi.org/10.4000/studifrancesi. 5985

Ce document a été généré automatiquement le 13 janvier 2021.

\section{(c) (†)}

Studi Francesi è distribuita con Licenza Creative Commons Attribuzione - Non commerciale - Non opere derivate 4.0 Internazionale. 


\title{
L'Image du Sápmi, Études comparées, textes réunis par Kajsa Andersson
}

\author{
Michel Arrous
}

\section{RÉFÉRENCE}

AA. VV., L'Image du Sápmi, Études comparées, textes réunis par Kajsa ANDERSSON, Örebro, Humanistica Oerebroensia, 2009 («Artes et linguae» n. 15), pp. 648.

1 Continuant ses publications sur l'image du Nord, Kajsa Andersson a regroupé dans ce volume imposant et généreusement illustré plus de trente études sur la Laponie ou, pour respecter l'appellation autochtone, au «Sápmi», peuple colonisé et balkanisé après 1750 , vivant dans la vaste zone comprise entre le monde scandinave et la péninsule de Kola. Sont tour à tour abordés l'histoire, l'ethnographie et la politique, les voyages (XVII ${ }^{\mathrm{e}}-\mathrm{XIX}^{\mathrm{e}}$ siècles), les arts plastiques, la musique, la littérature, les questions linguistiques et esthétiques. À l'attention des dix-neuviémistes, nous retiendrons, dans la deuxième et la troisième sections, supprime les voyages en 1839 de Léonie d'Aunet - Hugo n'était pas encore de ses admirateurs -, qui ne put qu'entrevoir le Cap Nord, et de son concubin puis mari, le peintre F.-A. Biard, séduit par le paysage arctique et dont de nombreux tableaux et dessins préparatoires sont reproduits (Christian MERIOT, Entre Voyage et Ethnographie: l'image du Same chez Léonie d'Aunet, pp. 186-209; Anne ASSERUD, François-Auguste Biard: le voyage d'un peintre de cour français dans le grand Nord, pp. 232-248). Pour sa part, Kajsa ANDERSSON a évoqué l'artiste suédoise peu connue Anna Nordlander (1848-1879) qui a souvent choisi des Sames comme modèles dans des tableaux pré-impressionnistes: si ses sujets s'inspirent de l'iconographie classique suédoise, ils n'en témoignent pas moins d'une juste compréhension de ce peuple (pp. 284-297). Signalons que le même auteur a consacré quelques pages à La Laponie vue par Selma Lagerlof et Marguerite Yourcenar (pp. 523-553). Marthe PEYROUX s'est intéressée aux grands voyageurs hyperboréens que furent Maupertuis et Linné et à un troisième, moins attendu et qui se contente d'une exploration livresque, Rémy de Gourmont, dont 
Chez les Lapons parut en 1890. Gourmont, qui a puisé à bien des sources, parvient à persuader son lecteur (Regards scientifiques, regard littéraire sur la lointaine Laponie, pp. 424-433). Maria WALECKA-GARBALINSKA, qui a publié Deux Émigrés en Suède, roman de Xavier Marmier (1849), associe et compare désert de sable et désert de neige dans Sahara et Laponie - imaginaire du désert et discours colonial dans les récits de voyages de Charles Martins et d'Eugène Goblet d'Alviella (pp. 480-497). Le premier, un naturaliste qui participa à l'expédition française de 1838-1839 et publia en 1866 Du Spitzberg au Sahara, comme le second, homme politique belge qui donna en 1873 Sahara et Laponie, étaient animés des mêmes ambitions scientifiques; mais, dans le contexte colonial de l'époque, leur perception de l'altérité «n'est pas toujours qu'une aventure exotique innocente». Dans ce beau volume, on peut regretter qu'aucune étude n'ait été consacrée à Xavier Marmier qui eut une juste appréhension du peuple Same, ni d'ailleurs à un auteur de moindre acabit, Léouzon Leduc, auteur de la première traduction française du Kalévala que pratiquèrent entre autres Mérimée, Dumas, Leconte de Lisle. Il est vrai que Maja LEHTONEN, dans Deux images de la Laponie chez Z. Topelius, (pp. 501-515), étudie la version peu fidèle que Léouzon Leduc donna en 1845 d'un récit de Topélius qu'il intitula La Fille du sorcier ou le roi Louis-Philippe en Laponie 1795, récit bien connu dont Biard s'inspira pour raconter à sa façon les aventures du duc d'Orléans. 